\title{
Real Time-PCR (RT-PCR) Positivity for SARS-CoV-2 in Suspected COVID-19 Patients Presented in a Tertiary Care Hospital
}

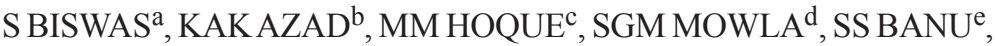 \\ R SHARMIN ${ }^{f}$, SM SHAMSUZZAMAN ${ }^{g}$
}

\begin{abstract}
:
Introduction: Corona Virus Disease 2019 (COVID-19) is caused by SARS-CoV-2, a newly emergent virus. World Health Organization declared COVID-19 as pandemic on March 11, 2020 for its rapid spreading. Not only to diagnose the disease (confirm case) but also to control and contain the transmission; test, trace and isolation are fundamental. RT-PCR for SARS-CoV-2 is used to detect and diagnose COVID-19 which started in Dhaka Medical College Hospital (DMCH) on $2^{\text {nd }}$ April 2020. In this study we described our observation of RT-PCR done in patients presented in DMCH in the first month after starting the test.
\end{abstract}

Methods: This observational, cross sectional study was done to find out the rate of RT-PCR positivity in suspected COVID -19 patients presented to DMCH from $2^{\text {nd }}$ April to $3^{\text {rd }}$ May, 2020 by the Department of Medicine in association with the Department of Virology. Data was collected from the registry book of the Department of Virology. The rate of RT-PCR for

Introduction:

From December, 2019 a new corona virus emerged and till $4^{\text {th }}$ June 4,2020 , there have been 6,397,294 confirmed cases and 383,872 deaths, reported to $\mathrm{WHO}^{1}$. For its aggressive, rapidly spreading contagious nature, on

a. Dr. Sarmistha Biswas, Associate Professor, Medicine, Dhaka Medical College.

b. Prof. Khan Abul Kalam Azad, Professor, Medicine and Principal, Dhaka Medical College.

c. Dr. Mohammad Mahfuzul Hoque, Assistant Professor, Medicine, Dhaka Medical College.

d. Dr. Syed Ghulam Mogni Mowla, Associate Professor, Medicine, Dhaka Medical College.

e. Prof. Sultana Shahana Banu, Head, Department of Virology, Dhaka Medical College.

f. Dr. Rabeya Sharmin, Assistant Professor, Virology, Dhaka Medical College.

g. Prof S. M. Shamsuzzaman, Head, Department of Microbiology, Dhaka Medical College.

Address of Correspondence: Dr. Sarmistha Biswas, Associate Professor of Medicine, Dhaka Medical College.

Mobile: +01712969025, Email: sarmibiswas365@gmail.com
SARS-CoV-2 positivity among the suspected COVID-19 patients and demographical variable was observed.

Results: Among the total studied patients ( $n=3206), 58.8 \%$ $(n=1886)$ was male and mean age was $37.7( \pm 14.38784)$ years. RT-PCR for SARS- CoV-2 was positive in $26.9 \%(n=864)$. Mean age was higher in patients positive for test (39.6 \pm 15.9 year vs. $37 \pm 14.4$ year). Male predominance was more marked in patients with positive PCR test (68.4 vs. 55.9).

Conclusion: High rate of positivity of RT PCR for SARSCoV-2 among the suspected patient for COVID 19 indicated high disease burden and transmission in this highly populated area in the early period of pandemic which should be considered as was alarming.

Key words: COVID-19, RT-PCR, SARS-CoV-2.

(J Bangladesh Coll Phys Surg 2020; 38: 67-70)

DOI: https://doi.org/10.3329/jbcps.v38i0.47439

March 11, 2020 World Health Organization (WHO) declared this novel Corona Virus Disease, 2019 (COVID$19)$ as a pandemic. ${ }^{2}$ This virus has also been named as SARS- CoV-2 by the International Committee of Taxonomy of Viruses (ICTV). ${ }^{3}$ Testing individuals for COVID- 19 is one of the crucial corner stone to fight against the pandemic. It is the only way a country can detect the cases for isolation, proper treatment, and contact tracing (IPC). Testing is our window onto the pandemic. That's why the value of testing was rightly focused by the chief of WHO on March 16, 2020 by the famous words, "Test, Test, and Test". Truly, we cannot fight a fire blindfolded. The world followed and great results were achieved by countries like China, South Korea, Singapore and even neighboring regions like Kerala in India. On the contrary, country like USA has come under fire from critics for slow gearing up of testing. Bangladesh with a low economic status has been thriving to increase testing since its first case detected on March 08,2020 . It is true that there has not been urgent enough escalation in testing in Bangladesh due to issues like unavailability of proper laboratory structures, low resource of equipment and funding, lack of trained 
personnel etc. Initially, Institute of Epidemiology, Disease Control and Research (IEDCR) of Bangladesh was the only center which started testing. According to the press releases of Directorate General of Health Services, Bangladesh, testing capacity has been increased from 92 daily (24-03-2020) to 9,554 tests daily (25-05-2020) being carried out in 48 labs and 35,585 cases have been detected from 2,54,068 tests, 4373 has recovered and 501 died till May 25 with 20.7\% infection rate and $1.4 \%$ death rate. ${ }^{4}$ Dhaka Medical College Hospital started RT-PCR testing from $2^{\text {nd }}$ April, 2020. This article is an initial observation over our results and insights up to now.

\section{Materials and Methods:}

This cross sectional study to find out the rate of RTPCR positivity in suspected COVID -19 patients was conducted in Dhaka Medical College Hospital from $2^{\text {nd }}$ April, 2020 to $3^{\text {rd }}$ May, 2020 by the Department of Medicine in association with the Department of Virology. The department of Virology has the BSL-2 facility which is the minimum requirement to do RT-PCR. The people who were presented as suspected COVID19 cases and came for RT-PCR for SARS-CoV-2 were included in the study. Data was collected from the registry book of the Department of Virology, Dhaka Medical College. Consent from the patients and ethical clearance from the institution were taken. The general objective of this study was to find out the rate of RTPCR for SARS-CoV-2 positivity among the suspected COVID-19 patients. The special objective was to assess the demographic variables of the RT-PCR positive confirmed COVID-19 cases and also the RT-PCR negative suspected cases. Data was analyzed using the SPSS 26 manufactured by IBM.

\section{Results:}

Total 3206 samples of nasal or pharyngeal swabs were taken in the study period of which $58.8 \%(\mathrm{n}=1886)$ were male and $40.8 \%(n=1304)$ were female. The sex mentioning was missed in 16 cases $(0.5 \%)$ [Table-I]

\section{Table-I}

\begin{tabular}{lcc}
\multicolumn{3}{c}{$\begin{array}{c}\text { Sex distribution of participants test } \\
\text { for RT PCR }(n=3206)\end{array}$} \\
Sex & Frequency & Percentage (\%) \\
\hline Female & 1304 & 40.7 \\
Male & 1886 & 58.8 \\
Missing data & 16 & 0.5 \\
\hline Total & 3206 & 100 \\
\hline
\end{tabular}

Among the participants, $26.9 \%(\mathrm{n}=864)$ patients were positive for RT-PCR for SARS-CoV-2; 72.7\% $(\mathrm{n}=2330)$ were negative and $12(0.4 \%)$ sample found to be indeterminate. [Table-II].

Table-II

\begin{tabular}{lcc}
\multicolumn{3}{r}{ Result of RT PCR for SARS COV-2 } \\
Test report & Frequency & Percentage (\%) \\
\hline Negative & 2330 & 72.7 \\
Positive & 866 & 26.9 \\
Indeterminate & 12 & 0.4 \\
\hline Total & 3206 & 100 \\
\hline
\end{tabular}

Among the RT-PCR positive SARS-CoV-2 cases the highest population remains in the 31-40 year age group (211; 24.36\%) followed by 21-30 year age group (206; $23.79 \%)$ and $41-50$ year group $(144 ; 16.63 \%)$ The lowest COVID- 19 detection was in the age group less than 10 years $(25 ; 2.89 \%)$ [Table- III] This is also the same in the suspected COVID cases who were RT-PCR negative. Here most of the cases came from 31-40 year age group (721, $30.94 \%$ ) followed by the $21-30$ year age group $(677,29.06 \%)$.

\section{Table-III}

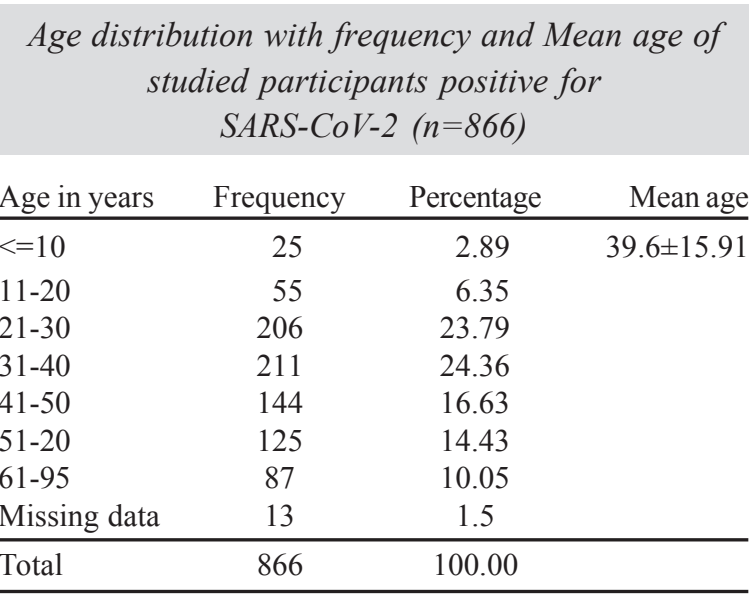

The mean age of the participants was 37.7 years (Standard deviation \pm 14.38 ). The mean age of the COVID19 patients was 39.6 years (standard deviation \pm 15.91 ) [Table-V].

In patients with RT-PCR Male was $68.4 \%(\mathrm{n}=592)$ and female was $31.6 \%(n=274)$ and in patients with RT-PCR male was $55.9 \%$ ( 1294$)$ and female was $44.1 \%(n=1020)$ [Table-VI]. 
Table-IV

Mean age distribution of participants studied ( $n=3206)$.

\begin{tabular}{lccc} 
Variable & Frequency & Mean & Standard Deviation. \\
\hline Mean Age among participants (Year) & 3,151 & 37.7 & \pm 14.38784 \\
Mean Age among RT-PCR positive COVID-19 cases (Year) & 853 & 39.6 & \pm 15.9108 \\
Age among RT-PCR negative suspected COVID-19 cases (Year) & 2,294 & 37.0 & \pm 13.71181 \\
\hline
\end{tabular}

Table-V

\begin{tabular}{lll}
\multicolumn{2}{c}{$\begin{array}{c}\text { Sex Distribution SARS-CoV-2 positive } \\
\text { and negative patient }\end{array}$} \\
RT PCR for SARS-Cov-2 & & Percentage $(\%)$ \\
\hline Positive $(\mathrm{n}=866)$ & Male & $68.4 \%(\mathrm{n}=592)$ \\
& Female & $31.6 \%(\mathrm{n}=274)$ \\
Negative $(\mathrm{n}=2330)$ & Male & $55.9 \%(\mathrm{n}=1294)$ \\
& Female & $44.1 \%(\mathrm{n}=1020)$ \\
\hline
\end{tabular}

\section{Discussion:}

Rapid collection and testing of appropriate specimen from the patients who meet the criteria of suspected case definition for COVID-19 is a priority for clinical management and outbreak control and suspected cases should be screened for the virus with nucleic acid amplification tests (NAAT), such as RT-PCR. ${ }^{5}$ Even if there is suspicion of co-infection, the cases must be tested for COVID-19 virus regardless of whether any other respiratory pathogen is found or not ${ }^{3}$. In this study $100 \%$ samples were taken from the respiratory tract. It is proven that respiratory samples for RT-PCR have the greatest yield; though it can be detected from other specimen like- blood, stool etc. ${ }^{6,7,8}$

In one- month case collection ( $2^{\text {nd }}$ April- $3^{\text {rd }}$ May2020), total number of study population was 3206. Most of them (99\%) were from Dhaka district. Because of lock down, very few cases came from the areas outside Dhaka. Among them, the male were $58.8 \%$, which is consistent with the study done by Li Q et al, where it is $56 \% ;{ }^{9}$ but more than the study done by Tao $\mathrm{Al}$ et al ${ }^{10}$ and Zhang $\mathrm{JJ}$ et $\mathrm{al}^{11}$ where the percentages were $46 \%$ and $50.7 \%$ respectively. The rate of positive RT-PCR was $26.9 \%$ [Table-2], what is lower than the study by Rui Liu et $\mathrm{al}^{12}$. Our rate is quite high in comparison with our national rate of positive RT-PCR for COVID-19 which is $21 \%$; but consistent with the finding of $\mathrm{WHO}$, where the highest attack rate was observed from $4^{\text {th }}$ April to $4^{\text {th }}$ May, 2020 in Dhaka district ${ }^{13}$.

Among the positive cases, most were in the 21-40 year age group [Table-3]. This finding is inconsistent with other studies. ${ }^{11,13}$ This finding is alarming for us because people of this age group are the young, income generating, mobile population of our country. So being more affected of this age group signifies that lockdown process, social distancing, personal hygiene and other preventive measures to combat this virus should be more strictly followed. This is also true about the RTPCR negative cases as because the test can be false negative. A negative result does not exclude the possibility of this infection and should not be used as sole indicator to treat the case. ${ }^{14}$ Clinical judgment is the prime need to manage a COVID-19 case.

The mean age of the positive cases was 37.7 years, which is much lower than the finding of Rui Liu et al. ${ }^{13}$ Mean age of patients with positive RT-PCR for SARS Cov-2 was higher than that of with negative test [Table5]. Marked male predominance in patients with positive test has important clinical implication [table-6], since male sex and old age is associated with increased mortality. ${ }^{15}$

\section{Limitations:}

This was the initial finding of an ongoing process. So the actual disease burden may not be ascertained from this study. Moreover, the information were collected from the registry of the concerned department. So, detailed information including clinical parameters and other lab findings could not be obtained. Further large scale, multi-centered study is a must to get the real national scenario of this pandemic.

\section{Conclusion:}

RT-PCR for SARS-CoV-2 remains the most specific test to confirm COVID-19 case unless and until other WHO 
recommended tests are available. High positivity rate of RT PCR for SARS-CoV-2 among suspected COVID 19 patients indicates transmission of infection is already in full swing. Larger epidemiological study is needed to characterize magnitude transmission and to estimate disease burden.

\section{Acknowledgement}

Prof. Dr. Md. Mujibur Rahman, Head, Department of Medicine, Dhaka Medical College

Dr. Brig. Gen A K M Nasir Uddin, Director, Dhaka Medical College Hospital

\section{References:}

1. https://covid19.who.int/

2. https://www.who.int/dg/speeches/detail/who-directorgeneral-s-opening-remarks-at-the-media-briefing-oncovid-19-11-march-2020

3. Alexander E, Gorbalenya, Susan C baker, Ralph S. Baric, Chris Lauber Andery M Leontovich et al. Severe acute respiratory syndrome-related coronavirus: The species and its viruses- a statement of the Coronavirus Study Group.bioRxiv2020.02.07.937862;doi: https//doi.org/ 10.1101/2020.02.07.937862.

4. https://corona.gov.bd/storage/pressreleases/May2020/ J9K4D7F7hilRjyfHAPek.pdf

5. https://www.who.int/publications/i/item/10665-331501

6. National Guidelines on Clinical Management of Coronavirus Disease 2019 (COVID-19). Directorate General of Health Services, Government Republic of Bangladesh. Version 7.0. $28^{\text {th }}$ May, 2020:11.

7. X Kaijin, C Hongliu, S Yihong et al. Management of Corona Virus Disease-19 (COVID-19): The Zheijiang experience. Jour Zheijiang Univ. DOI: 10,3785/j.issn.10089292.2020.02.02.
8. Wei Zhang, Rong Hui, du, Bei Li et al. Molecular and serological investigation of 2019 n COV infected patients: implication of multiple shedding routes, Emerging Microbes and Infections, 9:1, 386-389.9http//www.tandfontine.com/ doi/full/10.1080/22221751.2020.1729071.

9. Yong Zheng, cao Chen, Shuangli Zhu, Chang shu et al.Isolation of 2019-n COV from a stool specimen of a laboratory - Confirmed Case of the Coronavirus Disease 2019 (COVID-19),2020,CCDC weekly.21:8.

10. Li Q, Guan X, Wu P, Wang X, Zhou I, Tong Y et al. early Transmission dynamics in Wuhan, China of Novel Corinavirus- infected pneumonia. $N$ Engl J Med.2020;382:1199-207.doi: 10.1056/NEJMoa2001316.

11. Tao Al, Zhenlu Yang, Hongyan Hou, Chenao Zhan, Chong Chen etal. Correlation of Chest CT and RT-PCR Testing in Coronavirus Disease 2019 (COVID-19) in China: A report of 1014 cases. Radiology.2020 Feb 26. DOI; 10.1148/ radiol.2020200642.

12. JJ Zhang, X Dong, YY Cao, YD Yuan et al. Clinical Characteristics of 140 patients infected by SARS COV-2 in Wuhan, China. Allergy.2020.doi: 10.1111/all.14238.

13. Rui Liu, Huan Han, fang Liu, Zhihua, Lv, Kailang Wu et al. Positive rate of RT-PCR detection of SARS COV-2 infection in 4880 cases fron one hospital in wuhan, China from jan to Feb 2020. Clin Chim Acta. $7^{\text {th }}$ March 2020. Doi: 10.1016/j.cca.2020.03.009[Epub ahead of print].

14. Alireza Tahamtan, Abdollah Ardebili. Real Time RT-PCR in COVID -19 detection: issues affecting the results. Expert Rev Mol Diagn. 2020:1-2. Doi:10.1080/ 14737159.2020 .1757437 .

15. X Li, S Xu,M Yu, et al. Risk factors for severity and mortality in adult COVID-19 inpatients in Wuhan [published online ahead of print, 2020 Apr 12]. J Allergy Clin Immunol. 2020;S0091-6749(20)30495-4. doi:10.1016/j.jaci.2020.04.006 